J. Dairy Sci. 95:1337-1348

http://dx.doi.org/10.3168/jds.2011-4783

(C) American Dairy Science Association ${ }^{\circledR}, 2012$.

\title{
The effect of stocking rate and calving date on reproductive performance, body state, and metabolic and health parameters of Holstein-Friesian dairy cows
}

\author{
B. McCarthy, ${ }^{*} \dagger^{1}$ K. M. Pierce, $\dagger$ L. Delaby, $\ddagger$ A. Brennan, ${ }^{\star}$ and B. Horan ${ }^{\star}$ \\ ${ }^{*}$ Animal and Grassland Research and Innovation Centre, Teagasc Moorepark, Fermoy, Co. Cork, Ireland \\ †School of Agriculture, Food Science and Veterinary Medicine, University College Dublin, Belfield, Dublin 4, Ireland \\ fINRA, AgroCampus Ouest, UMR 1080, Production du Lait, F-35590 Saint-Gilles, France
}

\begin{abstract}
Two groups of Holstein-Friesian dairy cows with different mean calving dates (CD) were established from within the existing research herd at Moorepark (Teagasc, Ireland). Animals were assigned to either an early calving (mean CD February 12) treatment or a late calving (mean CD February 25) treatment. Animals within each CD treatment were randomly allocated to 1 of 3 stocking rate (SR) treatments, low (2.51 cows/ha), medium (2.92 cows/ha), or high (3.28 cows/ha), which were designed to represent 3 alternative whole-farm SR in a spring-calving, grass-based milk production system following abolition of the European Union milk quotas. A total of 138 spring-calving dairy cows, comprising 2 strains of Holstein-Friesian, North American (NA) and New Zealand (NZ), were used in each year (2009 and 2010). The effects of CD, SR treatment, genetic strain, and their interactions on reproductive performance, body weight, body condition score, blood metabolites, hormone and immunological parameters, and health status were analyzed. Stocking rate and CD had no effect on pregnancy rates, immunological parameters, or health status, although a tendency was observed for more reproductive intervention as SR increased. Earlier calving and increased SR also resulted in reduced body weight, body condition score, and metabolic status in early lactation. Strain of Holstein-Friesian also affected reproductive performance. The NZ strain tended to have a higher submission rate and $42 \mathrm{~d}$ pregnancy rate compared with the NA strain, and a strain by SR interaction was observed for pregnancy rate to first service. Earlier calving and increased SR can be achieved without adverse effects on overall pregnancy rates. The existence of a SR by strain interaction for several reproductive variables suggests that the smaller NZ strain is better adapted to increased SR systems.
\end{abstract}

Received July 28, 2011.

Accepted November 2, 2011.

${ }^{1}$ Corresponding author: brian.mccarthy@teagasc.ie
Key words: dairy cow, stocking rate, grass-based system, reproduction

\section{INTRODUCTION}

The proposed removal of European Union (EU) milk quotas in 2015 is expected to result in increased milk production in areas of competitive advantage such as Denmark, Ireland, and the Netherlands (Van Berkum and Helming, 2006). Lips and Rieder (2005) and O'Donnell et al. (2008) have hypothesized that milk production in Ireland could increase by between 30 and $50 \%$ post-quota because of the relatively increased competitiveness of milk production from grazed grass in Ireland. It is also acknowledged that a large increase in milk production within Irish grazing systems will require an increase in the genetic capability of the national herd in conjunction with enhanced grazing management practices to maximize milk production from grazed grass (Dillon et al., 2008).

Stocking rate (SR), defined as the number of animals per unit area of land during a defined period of time (cows/ha), is acknowledged as the primary driver of milk productivity within grass-based production systems (Hoden et al., 1991; Macdonald et al., 2008a; Baudracco et al., 2010). In a recent survey of commercial Irish dairy herds, O'Donnell et al. (2008) reported that, as the mean SR of 1.78 cows/ha was considerably below that recommended for Irish grazing systems (Dillon et al., 1995; McCarthy et al., 2007), real potential exists to increase SR and milk production from grazed grass on Irish dairy farms. Increasing SR results in a reduction in milk production per cow but an increase in milk production per hectare (Macdonald et al., 2008a; McCarthy et al., 2011), and both McCarthy et al. (2011) and Baudracco et al. (2010) have likened the effect of an SR increase to a reduction in daily herbage allowance. Dillon et al. (1995) reported that SR and calving date (CD) have a major effect on production and profitability in grass-based systems. However, the differences observed between CD in that study were the 
result of differences in both $\mathrm{CD}$ and feeding regimen as large quantities of additional supplementary feed were required for the earlier calving treatment (mean $\mathrm{CD}$ of January 23) compared with later calving (mean CD of March 15). To investigate the true interaction between $\mathrm{SR}$ and $\mathrm{CD}$ treatments from a grazing system, a range of SR and mean CD treatments must be compared on a common, predominantly grazing diet where minimal quantities of additional supplement are required in early lactation.

Grass-based systems of milk production require compact calving in spring to match feed supply and herd demand based on high rates of pregnancy within a short period following the start of breeding (Kennedy et al., 2003). It is imperative, therefore, that any SR increase or change in CD on Irish dairy farms must not negatively affect the reproductive efficiency or health of the grazing dairy herd. The reported effects of increasing SR on reproductive performance and animal health are inconsistent. Both King and Stockdale (1980) and Dillon et al. (1995) reported no significant effect of SR on reproductive performance, whereas Burke and Roche (2007) reported no effect of postpartum feed intake on the length of the postpartum anestrous period. In comparison, McDougall et al. (1995) and Macdonald et al. (2008a) observed an increase in the length of the postpartum anestrous period as SR increased. Reductions in individual animal DMI in higher SR systems, particularly in early lactation, may negatively affect reproductive performance and may be further aggravated by an inappropriate CD.

The objective of this study, therefore, was to quantify the effect of SR and CD on the reproductive performance, body condition, and health of modern high genetic potential (Economic Breeding Index; EBI) Holstein-Friesian (HF) dairy cows within Irish grassbased milk production systems following abolition of the EU milk quotas.

\section{MATERIALS AND METHODS}

This study was undertaken at Curtin's research farm, Animal and Grassland Research and Innovation center, Teagasc Moorepark, Ireland $\left(55^{\circ} 10^{\prime} \mathrm{N}, 8^{\circ} 16^{\prime} \mathrm{W}\right)$ over a 2 -yr period (2009 and 2010). The current analysis forms part of a larger overall study to examine the biological and economic efficiency of increasing SR and CD on grass-based, spring-calving milk production systems post-EU quotas.

\section{Animals}

The cows used in this experiment comprised 2 strains of HF of North American (NA) and New Zealand
(NZ) origin, as previously described by Coleman et al. (2009). In total, 275 lactations from 182 springcalving HF dairy cows were used as part of the trial, with 138 cows used in yr 1 and 2, respectively (45 and 36 primiparous and 93 and 102 pluriparous in yr 1 and 2, respectively; Table 1). In yr 2, 1 cow died from hypomagnesemia midway through the study and was subsequently replaced with another cow of similar BW to maintain the SR in that treatment. The data from the cow that died and that of her replacement were not included in the final analysis. The average EBI, milk, fertility, calving, beef, maintenance, and health sub-indices of the NA strain were $€ 103,46,46,19,-8$, 2 , and -2 , respectively, whereas the average EBI, milk, fertility, calving, beef, maintenance, and health subindices of the NZ strain was $€ 141,57,103,24,-25,19$, and -4 , respectively.

\section{Treatment Groups}

The experiment was a randomized block design with a $3 \times 2$ factorial arrangement of treatments. The 6 experimental treatments consisted of 3 SR $(2.51,2.92$, and 3.28 cows/ha) and 2 mean CD (February 12 and February 25). Two groups of high-EBI HF dairy cattle were established from within the existing Moorepark herd before the commencement of the 2008 breeding season. One group was randomly assigned to an early calving (EC; mean CD February 12) treatment and the other group to a late calving (LC; mean CD February 25) treatment. The EC treatment was established by commencing the breeding season on April 10 and finishing on July 10. The LC treatment was established by commencing the breeding season on April 24 and finishing on July 24. In 2009 and 2010, animals were retained within their respective calving treatments by breeding the LC treatment 2 wk later than the EC treatment. Cows within each CD group were then randomly assigned precalving (based on expected CD, parity, genetic strain, and EBI) to 1 of $3 \mathrm{SR}$ treatments, low (2.51 cows/ha; LSR), medium (2.92 cows/ ha; MSR), and high (3.28 cows/ha; HSR), which were designed to represent 3 alternative whole-farm SR in a spring-calving, grass-based milk production system. The MSR and HSR treatments were 16 and $31 \%$ higher, respectively, than the LSR treatment. The LSR treatment was designed to allow each animal to express its potential largely unrestricted by limitations in feed supply, whereas the aim of the MSR and HSR treatments was to investigate the potential to increase animal productivity per hectare by increasing SR and herbage utilization by grazing to lower postgrazing residual sward heights (PGRSH). 
Table 1. Number of cows and lactation records within each stocking rate, ${ }^{1}$ calving date, ${ }^{2}$ and genetic strain ${ }^{3}$ for each year of the study

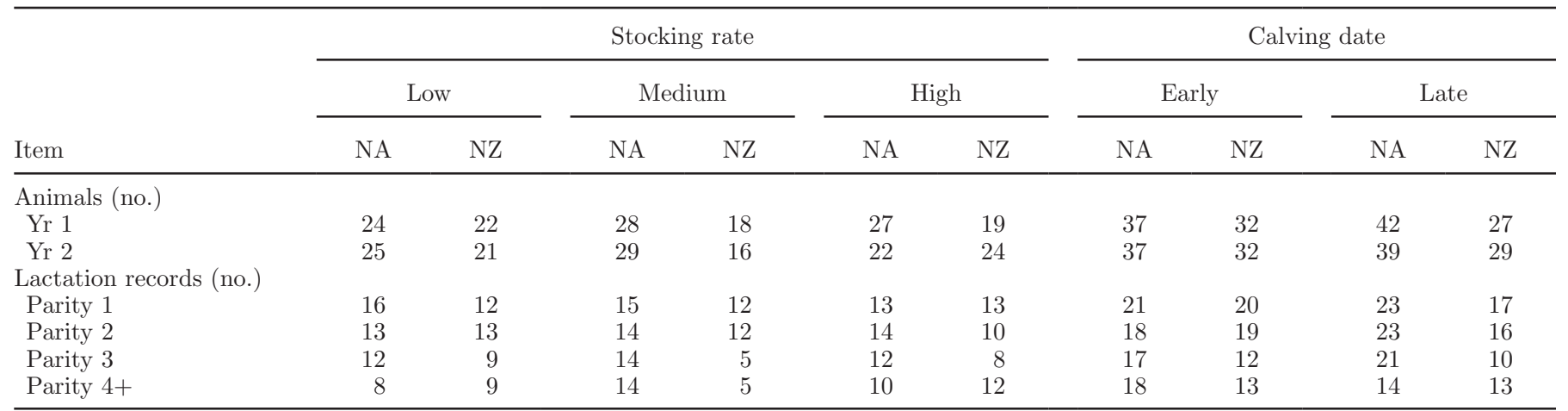

${ }^{1}$ Stocking rate: low $=2.51$ cows $/$ ha; medium $=2.92$ cows $/$ ha; high $=3.28$ cows $/$ ha

${ }^{2}$ Calving date: early $=$ February 12 ; late $=$ February 25 .

${ }^{3}$ Genetic strain: NA $=$ North American; NZ = New Zealand.

Concentrate supplementation was similar for all SR; however, according to the supplementation plan, less concentrate was fed to the $\mathrm{LC}$ treatments. Concentrate supplementation for all treatments commenced at 4 $\mathrm{kg} / \mathrm{d}$ postcalving and was reduced and removed only when grass supply exceeded animal demand for all treatments (usually in mid March). Concentrate and additional forage supplementation (in the form of baled silage) was reintroduced on several occasions during both years when grass supply was inadequate. The ingredient composition of the concentrate feed was barley $25 \%$, corn gluten $26 \%$, beet pulp $35 \%$, soybean meal $11 \%$, and minerals plus vitamins $3 \%$.

\section{Grazing Management}

A total of 48.1 ha of permanent grassland containing greater than $80 \%$ perennial ryegrass (Lolium perenne L.) was used for the duration of the experiment. A separate farmlet of 18 paddocks was created for each of the 6 treatments, and each farmlet was balanced for location and soil type. The farmlets were set up so that CD treatments within each SR grazed paddocks adjacent to each other and so facilitated common grazing management practice. The final structure was a 6 -farmlet experiment with each farmlet remaining in the same SR and CD treatment for the duration of the experiment. The total farmlet area of each LSR farmlet was 9.17 ha, compared with 7.87 ha for each MSR farmlet and 7.01 ha for each HSR farmlet. Artificial fertilizer application rates were kept constant for each SR at $250 \mathrm{~kg}$ of N/ ha per year. Cows were turned out to grass by day and night as they calved from early February in both years. As a result, the LC treatments had a lower daily SR during the calving period (late January to late April) as fewer cows calved in the LC groups on any given day during the calving period due to their later mean CD.
Grazing management was accomplished by weekly measurement of farmlet grass cover and growth rate for each SR, with grass quality maintained by removal of surplus grass as silage throughout the experiment (Coleman et al., 2010). A rotational grazing management system was practiced, and on-off grazing (Kennedy et al., 2009) was used as a management tool to facilitate grazing during periods of inclement weather. The residency time (ranging from 1.5 to $2.5 \mathrm{~d} /$ subpaddock) was determined by the achievement of predetermined target PGRSH of 4.5 to 5.0, 4.0 to 4.5, and 3.5 to $4.0 \mathrm{~cm}$ (measured using a folding pasture plate meter with a steel plate; Jenquip, Feilding, New Zealand) for LSR, MSR, and HSR, respectively, and each group was moved to the next paddock once this target was reached. Target pregrazing herbage mass $(>3.5 \mathrm{~cm}$ horizon) was identified separately for each SR according to the following formula:

$$
\begin{gathered}
\text { Target pregrazing herbage mass }=\{\text { stocking rate } \\
(\text { cows } / \text { ha }) \times \text { ideal rotation length } \times \text { daily herbage } \\
\text { allowance per cow }(\mathrm{kg} \text { of } \mathrm{DM} / \text { cow per } \mathrm{d})] \\
+ \text { residual herbage mass; } \mathrm{kg} \text { of } \mathrm{DM} \text { per ha }\} \text {. }
\end{gathered}
$$

Rotation lengths during the main grazing season (April to August) were allowed to vary between SR treatments. When actual pregrazing herbage mass in the next grazing paddock exceeded the target level, the paddock was skipped and herbage was harvested as silage. Calving date treatments within each SR grazed in sub-paddocks adjacent to each other and were managed according to common grazing management practices (pregrazing herbage mass, PGRSH, residency time, and rotation length). 


\section{Reproductive Management}

Approximately 35 to 42 d postcalving, each cow was examined using transrectal ultrasound imaging (Aloka SDD 500V scanner with a $5-\mathrm{MHz}$ transducer, Aloka Ltd., Tokyo, Japan) to assess the degree of uterine involution and detect ovarian or uterine disorders. The incidence of reproductive disorders (such as endometritis, pyometra, ovarian cysts, or failure to resume ovarian activity) was recorded. Anovulatory anestrous cows were treated with the following protocol: injection (i.m.) of GnRH [0.01 mg of buserelin (Receptal), Intervet, Dublin, Ireland] and insertion of an intravaginal progesterone-releasing device (Eazi-Breed CIDR containing $1.38 \mathrm{~g}$ of progesterone, Pfizer Animal Health, Dublin, Ireland). Seven days later, each cow received an injection (i.m.) of $\mathrm{PGF}_{2 \alpha}$ (Lutylase, Pfizer Animal Health), and the following day the CIDR was removed. Ovulation was induced by administering GnRH $36 \mathrm{~h}$ after CIDR withdrawal. Breeding commenced on April 25 for the EC groups in both years, whereas the LC groups commenced breeding on May 5 . Cows were visually observed for estrus at least 4 times daily for the duration of the breeding season. Tail paint was used as a heat detection aid and was reapplied when necessary. Artificial insemination was used throughout the 13 wk breeding season. Cows displaying estrus were inseminated regardless of $\mathrm{CD}$ and the same professional inseminator performed AI for each year of the study. Cows detected in estrus before the morning milking (0645 h) were inseminated that morning, whereas cows detected later that day were inseminated the following morning. All cows were inseminated with thawedfrozen semen, the quality of which had been verified before the start of the breeding season. Animals that were not observed in heat $21 \mathrm{~d}$ after AI were assumed to be pregnant, and pregnancy diagnosis was performed by transrectal ultrasound imaging approximately 30 to 36 and 60 to $66 \mathrm{~d}$ post-AI to determine pregnancy status and at $150 \mathrm{~d}$ after the beginning of the breeding season to determine overall pregnancy rates. During the breeding season, any cow not in calf at the time of ultrasound scanning was treated with the same CIDRbased protocol outlined above.

\section{$B W, B C S$, and Health and Reproductive Measurements}

Cow BW was recorded weekly upon exit from the milking parlor using an electronic scale (Tru-Test Ltd., Auckland, New Zealand). Body condition score was assessed every 3 wk on a scale of 1 to 5 in increments of 0.25 by the same individual throughout the study as outlined by Edmonson et al. (1989). Body weight and
BCS variables analyzed were BW and BCS at calving, nadir, mating start date (MSD), AI, and at the end of lactation. Body weight and BCS change from calving to nadir, AI, and MSD, and from nadir to the end of lactation were also analyzed. Reproductive measurements calculated and analyzed were mean CD (for both EC and LC treatments), $21 \mathrm{~d}$ submission rate (calculated based on an animal being served within the first $21 \mathrm{~d}$ of the breeding season irrespective of $\mathrm{CD}$ ), calving to first service interval (interval in days from calving to first service), calving to conception interval (interval in days from calving to conception), conception rate to first service (pregnant to first service and pregnant at the end of the breeding season), pregnancy rate after the first $42 \mathrm{~d}$ of the breeding season (pregnant at d 42 of breeding season and pregnant at the end of the breeding season), embryonic mortality (ultrasound scan: pregnant at d 30 post-AI but not pregnant at d 60 post-AI), and overall pregnancy rate (confirmed by ultrasound scanning $150 \mathrm{~d}$ after the start of the breeding season). All incidences of lameness, mastitis, calving difficulty, and reproductive intervention (e.g., washout, CIDR) were recorded in a database as they occurred. Somatic cell count was determined from consecutive morning and evening milkings once weekly from individual cows. The SCC was recorded using a flow cytometer (Bentley 3000; Bentley Instruments Inc., Chaska, MN).

\section{Blood Measurements}

Blood from all calved cows was sampled by coccygeal venipuncture at 3 time points each in yr 1 and 2 (corresponding to approximately 63,99 , and 233 DIM in yr 1 and 49, 98, and 225 DIM in yr 2). The 3 sampling occasions corresponded to significant biological calendar points for the entire animal population; namely, at peak lactation, during mo 1 of the mating season, and at final ultrasound pregnancy diagnosis, respectively. Two samples per cow per time point were collected. One sample was collected into 7 -mL lithium heparinized glass tubes (Vacutainer, Unitech Ltd., Dublin, Ireland) and was analyzed for metabolites and hormones, including glucose, BHBA, NEFA, insulin, and IGF. These samples were centrifuged within $2 \mathrm{~h}$ of collection for $15 \mathrm{~min}$ at $5^{\circ} \mathrm{C}$ and $1,470 \times g$. The plasma was then split into borosilicate glasses and stored at $-20^{\circ} \mathrm{C}$ until analysis. Glucose, BHBA, and NEFA concentrations were determined by enzymatic calorimetry using $A B X$ Mira Auto analyzer (ABX Mira, Montpellier, France). Plasma insulin concentrations were quantified using fluoro-immunoassay (AutoDELFIA, PerkinElmer Life and Analytical Sciences, Turku, Finland). Insulin-like growth factor concentrations were quantified using RIA after an acid-ethanol extraction. The second set of blood 
samples were collected into $10-\mathrm{mL}$ sterile glass tubes containing $\mathrm{K}_{3}$ EDTA (Vacutainer) and were analyzed for total white blood cell count as well as a differential count, including neutrophil and lymphocyte counts. These analyses were undertaken using an automated electronic particle analyzer (Abbott Cell Dyn 3500, CD 3500 Hematology analyzer, Abbott Laboratories, Abbott Park, IL) at the Irish Equine Centre laboratories (Johnstown, Naas, Co. Kildare, Ireland) on the same day as the blood samples were collected.

\section{Statistical Analysis}

Dietary Details. The effects of SR, CD, and year on daily herbage allowance, total feed allowance, and postgrazing height were determined using mixed models (Proc Mixed, SAS Institute, 2006) with rotation included as a repeated effect. A compound symmetry covariance structure among records within paddock provided the best fit to the data. The amount of concentrate fed during the prebreeding period and during the breeding period was determined using linear models (Proc GLM, SAS Institute, 2006) with the effect of SR, $\mathrm{CD}$, and year included in the model.

$B W, B C S$, and Health and Reproductive Performance. The effects of SR and CD on BW, BCS, and calving day of year, calving to first service interval, and calving to conception interval were analyzed using general linear models (Proc GLM, SAS Institute, 2006). The effects of year, parity, SR, CD, genetic strain, and their interactions were tested. Calving day centered within CD treatment was included as a covariate in each model, whereas BW and BCS at calving centered within genetic strain were also included as covariates for nadir $\mathrm{BW}$ and $\mathrm{BCS}, \mathrm{BW}$ and $\mathrm{BCS}$ at MSD, BW and BCS at AI, and BW and BCS at the end of lactation. For BW and BCS change variables, the predicted milk production potential centered within strain was used as a covariate instead of BW and BCS at calving centered within strain. Number of services per cow was analyzed using the Kruskal-Wallis nonparametric test (Proc NPAR1WAY, SAS Institute, 2006). A logistic regression model (Proc Logistic, SAS Institute, 2006) that included the effects of SR, CD, genetic strain, and parity, with predicted fertility potential (fertility sub-index) also included as a covariate, was used to determine $21 \mathrm{~d}$ submission rates, pregnancy rates to first service, pregnancy rates to second service, $42 \mathrm{~d}$ pregnancy rates, embryo mortality, and overall pregnancy rates. A mean SCC was calculated for each cow in both years of the experiment by calculating the geometric mean of the SCC for each cow. Health and reproductive disorders and mean SCC were analyzed using a logistic regression model (Proc Logistic, SAS Institute, 2006), which included the effects of SR, CD, genetic strain, and parity, with health sub-index included in the model as a covariate.

Blood Hormone, Metabolite, and Immunological Parameters. All blood hormone, metabolite, and immunological variables were tested for normality both visually and analytically using the univariate procedure in SAS (Proc Univariate, SAS Institute, 2006). The natural logarithm transformation of neutrophils, neutrophil to lymphocyte ratio, BHBA, NEFA, and insulin was used to normalize the distributions. Analysis was undertaken on the transformed, normally distributed data, and back-transformed results are presented. The effect of SR, CD, genetic strain, sampling time point, and parity, with calving day centered within CD treatment included as a covariate, on the blood parameters was determined using mixed models (Proc Mixed, SAS Institute, 2006), with sampling time point included as a repeated effect. A compound symmetry covariance structure among records within cow provided the best fit to the data.

\section{RESULTS}

\section{Effect of SR and CD on Grazing Management and Concentrate Input over 2 Experimental Years}

Because no interaction was found between SR and CD and herbage management or concentrate inputs from calving to the end of breeding, only the main effects are detailed in Table 2. Herbage allowance and total feed allowance were similar for MSR and HSR, whereas LSR had a higher daily herbage and total feed allowance during the prebreeding period. The SR groups did not differ in the amount of concentrate fed. The LC groups had a higher $(P<0.01)$ daily herbage allowance, total feed allowance, and PGRSH compared with EC groups during the prebreeding period. However, the EC treatments had a higher total concentrate intake compared with LC (205 vs. $185 \mathrm{~kg}$ ). During the breeding season, daily herbage allowance, total feed allowance, and PGRSH were greatest for the LSR, intermediate for the MSR, and lowest for the HSR $(P<0.001)$, whereas concentrate fed between treatments did not differ. Year had a significant effect on all grazing management and concentrate input characteristics except for PGRSH during the breeding period.

\section{Reproductive Performance}

No interaction was observed between SR and CD for any of the reproductive variables analyzed; therefore, only main effects are presented (Table 3 ). Stocking rate had no effect on mean $\mathrm{CD}$, calving to service inter- 


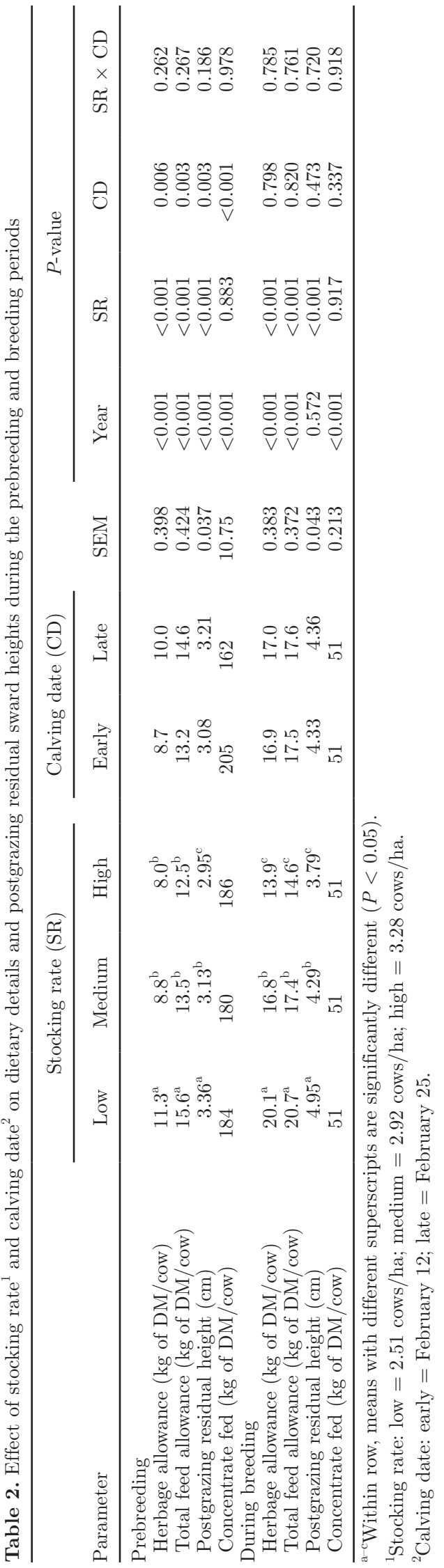

val, calving to conception interval, or the number of services per cow. Neither CD nor strain of HF had an effect on any of the reproductive variables measured. The effect of SR, CD, and strain on the binary reproductive traits are presented in Table 4. Stocking rate had no effect on any of the reproduction variables measured (overall mean pregnancy rates at the end of the breeding season were 83,78 , and $80 \%$ for LSR, MSR, and HSR, respectively) with the exception of embryo mortality and requirement for reproductive treatment. The LSR treatment had increased odds of embryo loss compared with MSR or HSR, and the odds of animals requiring reproductive treatments tended to increase as SR increased. The LSR had higher embryo losses (9.8\%) compared with MSR and HSR (4.4 and 1.1\%, respectively), whereas the HSR and MSR received more reproductive treatments (30.8 and $33.7 \%$, respectively) compared with LSR (18.5\%). Calving date had no effect on any of the reproductive variables measured with the exception of requirement for reproductive treatments. The LC treatments had increased odds of requiring reproductive intervention ( $22.4 \%$ of the EC group required reproductive intervention compared with $32.9 \%$ for the LC group).

Strain had no effect on any of the reproductive variables after correcting for predicted fertility potential (fertility sub-index). However, a tendency was observed for the NZ strain to have increased odds of being submitted for AI and being pregnant $42 \mathrm{~d}$ after the start of the breeding season. The NZ animals tended to have higher submission rates than the NA animals (88.3 vs. $74.8 \%)$ and a higher $42 \mathrm{~d}$ pregnancy rate (69.2 vs. $52.3 \%$ ). The interaction between strain of HF and SR for reproductive performance is presented in Table 5 . Reproductive intervention was similar for the NZ cows across all SR treatments (18.6, 20.6, and 23.3\% for LSR, MSR, and HSR, respectively), whereas the odds of NA animals requiring reproductive intervention tended to increase as SR increased $(18.4,36.8$, and $42.9 \%$ for NA cows in LSR, MSR, and HSR, respectively). A significant strain by SR interaction was observed for pregnancy rate to first service, with the NA HF having a higher pregnancy rate in the LSR and MSR (51 and $49 \%$, respectively) compared with the NZ animals (42 and $38 \%$, respectively) and the NZ achieving a higher pregnancy rate to first service than NA in the HSR (65 vs. $31 \%)$.

\section{$B W$ and $B C S$}

The effects of SR, strain, and CD on BW and BCS characteristics from calving to the end of lactation are detailed in Table 6. Stocking rate had a significant effect on all $\mathrm{BW}$ characteristics with the exception of BW at 
Table 3. Effect of stocking rate $^{1}$ and calving date ${ }^{2}$ on reproductive performance

\begin{tabular}{|c|c|c|c|c|c|c|c|c|c|}
\hline Parameter & \multicolumn{3}{|c|}{ Stocking rate } & SEM & $P$-value & \multicolumn{2}{|c|}{ Calving date } & SEM & $P$-value \\
\hline Calving date & Feb 19 & Feb 19 & Feb 18 & 2.5 & 0.923 & Feb 12 & Feb 25 & 1.9 & $<0.001$ \\
\hline Calving to conception interval (d) & 100.2 & 100.6 & 96.7 & 3.68 & 0.704 & 99.9 & 98.4 & 3.00 & 0.721 \\
\hline Services per cow (no.) & 1.83 & 1.97 & 1.84 & 0.113 & 0.923 & 1.86 & 1.90 & 0.093 & 0.201 \\
\hline
\end{tabular}

${ }^{1}$ Stocking rate: low $=2.51$ cows $/$ ha; medium $=2.92$ cows $/$ ha; high $=3.28$ cows $/$ ha.

${ }^{2}$ Calving date: early $=$ February 12 ; late $=$ February 25 .

calving. The HSR and MSR lost more BW from calving to AI (28 and $20 \mathrm{~kg}$, respectively) and from calving to nadir (63 and $63 \mathrm{~kg}$, respectively) compared with the LSR ( 7 and $49 \mathrm{~kg}$, respectively). Consequently, the HSR and MSR treatments had a lower BW $(P<0.05)$ at nadir (445 and $446 \mathrm{~kg}$, respectively), at AI (480 and $488 \mathrm{~kg}$, respectively), and at the end of lactation (546 and $554 \mathrm{~kg}$, respectively) compared with LSR (460, 502, and $571 \mathrm{~kg}$ ). The EC groups were lighter at nadir BW $(446 \mathrm{~kg})$ and at $\mathrm{AI}(482 \mathrm{~kg})$, and lost more BW from calving to AI (26 kg) and from calving to nadir $(63 \mathrm{~kg})$ compared with the LC group $(455,498,10$, and $54 \mathrm{~kg}$, respectively). The EC treatment also gained more $\mathrm{BW}$ from nadir to the end of lactation compared with LC $(115$ vs. $99 \mathrm{~kg})$. Animals of the NA strain were heavier at nadir $(454 \mathrm{~kg})$ and at AI (494 kg) compared with those of the NZ strain (446 and $486 \mathrm{~kg}$, respectively), although BW change was unaffected by strain.

The HSR treatment had a lower BCS $(P<0.01)$ at nadir (2.67) compared with the LSR (2.77), and the MSR was intermediate (2.71). A tendency $(P<0.13)$ was observed for cows to lose more condition from calving to nadir and for BCS to be reduced at AI and at the end of lactation as SR increased. Calving date had no effect on BCS except at the end of lactation and BCS change from nadir to the end of lactation, which was increased with the EC treatment. Genetic strain had a significant effect on BCS as the NZ cows were fatter at MSD, at AI, at nadir, and at the end of lactation and lost less condition from calving to AI $(P<0.05)$. We observed no interaction between SR and CD or SR and strain for any of the BW or BCS variables.

\section{Blood Parameters}

The effect of SR, CD, and strain on blood hormone and metabolite parameters is presented in Table 7 . The LSR had the lowest $(P<0.05)$ BHBA concentration $(0.40 \mathrm{mmol} / \mathrm{L})$ and the highest $(P<0.05)$ concentrations of IGF $(139 \mathrm{ng} / \mathrm{mL})$ and insulin $(2.95 \mu \mathrm{IU} / \mathrm{mL})$. The HSR and MSR had the highest BHBA concentration and the lowest IGF and insulin concentrations $(0.42 \mathrm{mmol} / \mathrm{L}, 120 \mathrm{ng} / \mathrm{mL}$, and $2.55 \mu \mathrm{IU} / \mathrm{mL}$, and 0.43 $\mathrm{mmol} / \mathrm{L}, 116 \mathrm{ng} / \mathrm{mL}$, and $2.71 \mu \mathrm{IU} / \mathrm{mL}$, respectively). The EC group had higher $(P<0.05)$ IGF $(131 \mathrm{ng} / \mathrm{mL})$ and insulin $(2.90 \mu \mathrm{IU} / \mathrm{mL})$ concentrations compared with the LC group $(119 \mathrm{ng} / \mathrm{mL}$ and $2.57 \mu \mathrm{IU} / \mathrm{mL})$. The EC treatments also had a lower $(P<0.05)$ NEFA $(0.18$ $\mathrm{mmol} / \mathrm{L})$ concentration than the LC $(0.20 \mathrm{mmol} / \mathrm{L})$. The NZ strain had higher $(P<0.01)$ IGF $(134 \mathrm{ng} / \mathrm{mL})$ and insulin $(2.92 \mu \mathrm{IU} / \mathrm{mL})$ concentrations compared with NA (116 ng/mL and $2.55 \mu \mathrm{IU} / \mathrm{mL}$, respectively). A strain by SR interaction was evident for glucose concentration as NA cows had the lowest concentration in

Table 4. Effect of stocking rate, ${ }^{1}$ calving date, ${ }^{2}$ and genetic strain ${ }^{3}$ on odds ratios ${ }^{4}$ for reproductive performance variables (95\% CI in parentheses)

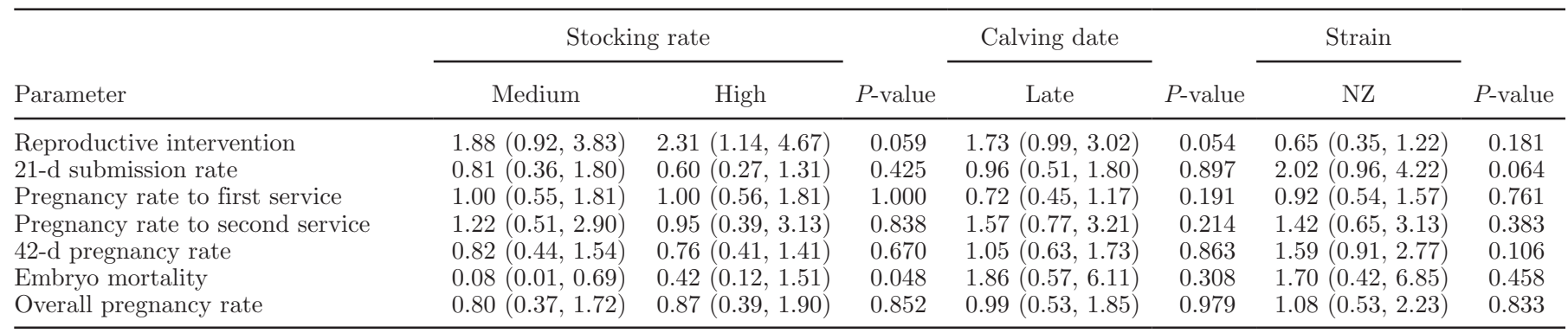

${ }^{1}$ Stocking rate: low $=2.51 \mathrm{cows} /$ ha; medium $=2.92 \mathrm{cows} /$ ha; high $=3.28 \mathrm{cows} /$ ha.

${ }^{2}$ Calving date: early $=$ February 12 ; late $=$ February 25 .

${ }^{3}$ Genetic strain: NA $=$ North American; NZ = New Zealand.

${ }^{4}$ Low stocking rate, early calving, and NA strain were used as reference categories. 
Table 5. Effect of stocking rate $(\mathrm{SR})^{1}$ and genetic $\operatorname{strain}^{2}$ on odds ratios ${ }^{3}$ for reproductive performance variables (95\% CI in parentheses)

\begin{tabular}{|c|c|c|c|c|c|c|}
\hline Parameter & $\frac{\text { Low SR }}{\text { NZ }}$ & \multicolumn{2}{|c|}{ Medium SR } & \multicolumn{2}{|c|}{ High SR } & $P$-value \\
\hline Reproductive intervention & $1.21(0.40,3.64)$ & $2.55(1.02,6.43)$ & $1.44(0.46,4.54)$ & $3.42(1.33,8.76)$ & $1.62(0.55,4.77)$ & 0.093 \\
\hline Pregnancy rate to first service & $0.51(0.21,1.23)$ & $0.97(0.45,2.12)$ & $0.46(0.18,1.16)$ & $0.41(0.18,0.97)$ & $1.36(0.56,3.29)$ & 0.036 \\
\hline Pregnancy rate to second service & $2.41(0.67,8.70)$ & $1.74(0.51,5.94)$ & $2.11(0.55,8.01)$ & $1.45(0.45,4.74)$ & $1.32(0.30,5.82)$ & 0.799 \\
\hline 42 -d pregnancy rate & $1.30(0.52,3.27)$ & $0.89(0.40,2.00)$ & $0.88(0.34,2.27)$ & $0.52(0.23,1.20)$ & $1.61(0.62,4.18)$ & 0.243 \\
\hline
\end{tabular}

${ }^{1}$ Stocking rate: low $=2.51 \mathrm{cows} /$ ha; medium $=2.92 \mathrm{cows} /$ ha; high $=3.28 \mathrm{cows} /$ ha.

${ }^{2}$ Genetic strain: NA = North American; NZ = New Zealand.

${ }^{3}$ The low SR, NA strain was used as the reference category.

${ }^{4}$ There was no incidence of embryo mortality in this treatment; therefore, it was excluded from the analysis for this variable.

the HSR $(3.17 \mathrm{mmol} / \mathrm{L})$ with similar concentrations at LSR and MSR (3.24 and $3.25 \mathrm{mmol} / \mathrm{L}$, respectively). In contrast, NZ cows had the highest glucose concentration in the HSR treatment $(3.25 \mathrm{mmol} / \mathrm{L})$ and the lowest concentration in the MSR $(3.13 \mathrm{mmol} / \mathrm{L})$. Neutrophil and lymphocyte counts were within the normal range for all SR and CD treatments $\left(2.90 \times 10^{9} / \mathrm{L}\right.$ and $3.40 \times 10^{9} / \mathrm{L}$ for neutrophil and lymphocyte counts, respectively).

\section{Health Aspects}

Stocking rate or CD had no effect on the incidence of clinical mastitis, lameness, or calving difficulty, or on mean SCC. Strain had no effect on any of the health parameters analyzed.

\section{DISCUSSION}

\section{Effect of SR and $C D$}

The results of the present study indicate that within the range of production systems investigated, increasing SR had no effect on overall pregnancy rates and health status of dairy cows on a predominantly grass-based diet. The overall reproductive performance was similar to that reported in previous experiments with HF dairy cattle at the same research site (Horan et al., 2004; Coleman et al., 2009) but lower than that reported in recent studies using crossbred animals (Auldist et al., 2007). The results were in agreement with Macdonald et al. (2008a) and Dillon et al. (1995) and showed that increasing SR had no significant effect on overall pregnancy rates. Macdonald et al. (2008a) reported a tendency for the proportion of cows submitted for AI in the first $3 \mathrm{wk}$ of the breeding season to decline as SR increased. Similarly, in this study, we observed an increase in the requirement for reproductive treatments as SR increased, particularly among NA HF animals.
Macdonald et al. (2008a) concluded that although herbage availability had been significantly reduced at the higher SR, sufficient herbage was available to all SR in the prebreeding period. Both McDougall et al. (1995) and Macdonald et al. (2008a) observed that increased SR may be associated with longer periods of anestrous and a decline in submission rates. Similar to SR, CD had no effect on overall pregnancy rate; however, LC groups required more reproductive intervention than EC groups.

Both Baudracco et al. (2010) and McCarthy et al. (2011) have likened an increase in SR to a reduction in daily herbage allowance. In the current study, increasing SR resulted in reduced daily herbage allowance during both the prebreeding and the breeding season (Table 2) and consequently potentially resulted in reduced herbage DMI (Wales et al., 1998). The EC treatment also had a reduced daily herbage allowance and total feed allowance (Table 2) before the breeding season compared with the LC treatment, where proportionally fewer animals were calved in each week in advance of the breeding season. The LC treatment received a similar daily area allocation to EC and consequently achieved an increased herbage allowance per cow per day in early lactation. The EC treatment received more concentrate supplementation in early lactation as more cows calved earlier. However, EC had a lower total daily feed allowance compared with LC treatments reflecting the important biological effect of a 13-d delay in mean CD on feed availability within a predominantly grassbased spring-calving feed system.

The results indicate that although the LC treatment had a higher feed allowance in early lactation arising from delaying CD (and reducing grass demand relative to supply during this period), this had no effect on subsequent reproductive performance. Macdonald et al. (2008a) reported that when cow feed intake was reduced by $1,551 \mathrm{~kg}$ of $\mathrm{DM} / \mathrm{cow}$ per year (equivalent 
Table 6. Effect of stocking rate $(\mathrm{SR}),{ }^{1}$ genetic strain $(\mathrm{S}),{ }^{2}$ and calving date $(\mathrm{CD})^{3}$ on BW and BCS

\begin{tabular}{|c|c|c|c|c|c|c|c|c|c|c|c|c|c|}
\hline \multirow[b]{2}{*}{ Parameter } & \multicolumn{3}{|c|}{ NA } & \multicolumn{3}{|c|}{$\mathrm{NZ}$} & \multicolumn{2}{|c|}{ Calving date } & \multirow[b]{2}{*}{ SEM } & \multicolumn{4}{|c|}{$P$ value } \\
\hline & Low & Medium & High & Low & Medium & High & Early & Late & & $\mathrm{SR}$ & $\mathrm{CD}$ & $\mathrm{S}$ & $\mathrm{S} \times \mathrm{SR}$ \\
\hline BW calving $(\mathrm{kg})$ & 505 & 508 & 509 & 504 & 503 & 499 & 504 & 505 & 7.948 & 0.981 & 0.843 & 0.414 & 0.853 \\
\hline Nadir BW (kg) & 462 & 455 & 446 & 457 & 437 & 445 & 446 & 455 & 4.457 & 0.002 & 0.013 & 0.033 & 0.144 \\
\hline BW at mating start date $(\mathrm{kg})$ & 503 & 492 & 482 & 499 & 479 & 479 & 479 & 498 & 4.487 & $<0.001$ & $<0.001$ & 0.081 & 0.463 \\
\hline BW at AI (kg) & 504 & 498 & 480 & 500 & 478 & 481 & 482 & 498 & 4.749 & $<0.001$ & $<0.001$ & 0.048 & 0.076 \\
\hline BW at the end of lactation $(\mathrm{kg})$ & 575 & 565 & 541 & 566 & 543 & 552 & 560 & 554 & 6.373 & 0.006 & 0.180 & 0.186 & 0.034 \\
\hline BW change calving to AI ( $\mathrm{kg})$ & -7.6 & -14.1 & -32.9 & -6.0 & -26.2 & -22.9 & -26.4 & -10.2 & 5.833 & 0.001 & 0.001 & 0.974 & 0.170 \\
\hline BW change calving to nadir ( $\mathrm{kg}$ ) & -49.4 & -58.0 & -67.2 & -48.5 & -68.2 & -58.7 & -62.5 & -54.2 & 5.534 & 0.014 & 0.060 & 0.954 & 0.248 \\
\hline BW change nadir to end $(\mathrm{kg})$ & 114 & 111 & 96 & 109 & 107 & 107 & 115 & 99 & 5.598 & 0.178 & 0.001 & 0.864 & 0.257 \\
\hline BCS calving & 3.20 & 3.21 & 3.21 & 3.31 & 3.21 & 3.25 & 3.21 & 3.25 & 0.034 & 0.520 & 0.239 & 0.083 & 0.230 \\
\hline Nadir BCS & 2.73 & 2.67 & 2.61 & 2.81 & 2.76 & 2.73 & 2.73 & 2.71 & 0.032 & 0.008 & 0.364 & $<0.001$ & 0.778 \\
\hline BCS at mating start date & 2.94 & 2.94 & 2.91 & 3.06 & 3.02 & 2.96 & 2.96 & 2.98 & 0.031 & 0.104 & 0.487 & $<0.001$ & 0.574 \\
\hline $\mathrm{BCS}$ at $\mathrm{AI}$ & 2.90 & 2.87 & 2.84 & 3.04 & 2.97 & 2.95 & 2.94 & 2.92 & 0.035 & 0.079 & 0.676 & $<0.001$ & 0.841 \\
\hline BCS at the end of lactation & 2.94 & 2.91 & 2.85 & 3.06 & 2.98 & 3.01 & 3.00 & 2.92 & 0.037 & 0.126 & 0.011 & $<0.001$ & 0.522 \\
\hline BCS change calving to AI & -0.29 & -0.34 & -0.38 & -0.25 & -0.26 & -0.24 & -0.26 & -0.32 & 0.049 & 0.723 & 0.142 & 0.031 & 0.641 \\
\hline BCS change calving to nadir & -0.47 & -0.55 & -0.60 & -0.48 & -0.47 & -0.51 & -0.49 & -0.54 & 0.040 & 0.111 & 0.142 & 0.099 & 0.434 \\
\hline BCS change nadir to end & 0.22 & 0.24 & 0.25 & 0.24 & 0.24 & 0.28 & 0.27 & 0.22 & 0.030 & 0.484 & 0.032 & 0.517 & 0.834 \\
\hline
\end{tabular}

${ }^{1}$ Stocking rate: low $=2.51$ cows $/$ ha; medium $=2.92$ cows $/$ ha; high $=3.28$ cows $/$ ha.

${ }^{2}$ Genetic strain: NA = North American; NZ = New Zealand.

${ }^{3}$ Calving date: early $=$ February $12 ;$ late $=$ February 25.

Table 7. Effect of stocking rate (SR), ${ }^{1}$ genetic strain $(\mathrm{S}),{ }^{2}$ and calving date $(\mathrm{CD})^{3}$ on blood metabolite and hormone parameters (mean of 3 sampling time points: 56 , 99 , and 229 mean DIM)

\begin{tabular}{|c|c|c|c|c|c|c|c|c|c|c|c|c|c|}
\hline \multirow[b]{2}{*}{ Parameter } & \multicolumn{3}{|c|}{ NA } & \multicolumn{3}{|c|}{$\mathrm{NZ}$} & \multicolumn{2}{|c|}{ Calving date } & \multirow[b]{2}{*}{ SEM } & \multicolumn{4}{|c|}{$P$-value } \\
\hline & Low & Medium & High & Low & Medium & High & Early & Late & & $\mathrm{SR}$ & $\mathrm{CD}$ & S & $\mathrm{S} \times \mathrm{SR}$ \\
\hline \multicolumn{14}{|l|}{ Blood metabolite } \\
\hline $\operatorname{BHBA}^{4}(\mathrm{mmol} / \mathrm{L})$ & 0.40 & 0.44 & 0.42 & 0.39 & 0.43 & 0.41 & 0.41 & 0.42 & 0.031 & 0.015 & 0.420 & 0.395 & 0.990 \\
\hline Glucose $(\mathrm{mmol} / \mathrm{L})$ & 3.24 & 3.25 & 3.17 & 3.21 & 3.13 & 3.25 & 3.22 & 3.20 & 0.035 & 0.592 & 0.613 & 0.379 & 0.016 \\
\hline $\mathrm{NEFA}^{4}(\mathrm{mmol} / \mathrm{L})$ & 0.18 & 0.20 & 0.18 & 0.19 & 0.19 & 0.19 & 0.18 & 0.20 & 0.055 & 0.841 & 0.046 & 0.928 & 0.720 \\
\hline \multicolumn{14}{|l|}{ Hormone } \\
\hline IGF (ng/mL) & 132 & 109 & 106 & 145 & 122 & 134 & 131 & 119 & 6.626 & 0.001 & 0.036 & 0.001 & 0.426 \\
\hline $\operatorname{Insulin}^{4}(\mu \mathrm{IU} / \mathrm{mL})$ & 2.83 & 2.43 & 2.40 & 3.07 & 3.02 & 2.70 & 2.90 & 2.57 & 0.055 & 0.029 & 0.007 & 0.002 & 0.452 \\
\hline
\end{tabular}

خे ${ }^{1}$ Stocking rate: low $=2.51 \mathrm{cows} /$ ha; medium $=2.92 \mathrm{cows} /$ ha; high $=3.28 \mathrm{cows} /$ ha

${ }^{2}$ Genetic strain: NA $=$ North American; NZ = New Zealand.

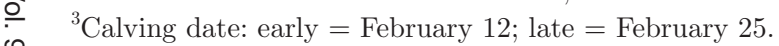

G ${ }^{4}$ Indicates variables that required a natural log-transformation for analysis; back-transformed data are presented. 
to a $28.5 \%$ reduction in annual grass DMI) in an increased SR treatment, reproductive performance was unaffected. These results are consistent with several recent studies, which have reported no effect of increasing grass and total DMI in early lactation on reproductive performance (Horan et al., 2004; Coleman et al., 2009; Delaby et al., 2009) despite beneficial effects on metabolic status (Pedernera et al., 2008; de Feu et al., 2009). Burke et al. (2010) also reported that an acute feed restriction at the start of the breeding season caused a reduction in submission rates and $3 \mathrm{wk}$ and $6 \mathrm{wk}$ pregnancy rates but had no effect on pregnancy rates to first and second services or on the final pregnancy rate.

Although increasing SR may have been associated with an increased requirement for reproductive treatment, the LSR treatment incurred the highest level of embryonic losses, which finally resulted in no effect of SR on overall pregnancy rates. This result is consistent with recent findings by Cutullic et al. (2011) and suggests that the inconsistent relationship between feeding level and reproductive performance in the literature can be explained by contradictory effects of feeding level on various aspects of the reproductive process. Using Normande and HF cows within French grazing systems, Cutullic et al. (2011) reported that although reduced feed allowances result in reduced BCS, the reproductive capacity of the animal is not detrimentally affected because milk production is also reduced. Whereas cows in LSR had a higher herbage allowance and total feed allowance both prebreeding and during the breeding season, resulting in reduced $\mathrm{BW}$ and $\mathrm{BCS}$ loss and a lower requirement for reproductive intervention compared with both the MSR and HSR treatments, they also produced more milk. B. McCarthy (unpublished data), in a subset of data from the current study, observed increased milk production with the LSR $(5,597$ $\mathrm{kg}$ per cow) compared with the MSR and HSR $(5,045$ and $4,975 \mathrm{~kg}$ per cow, respectively). Because increased milk production has been associated with increased embryonic loss (Grimard et al., 2006), cows in the LSR treatment were unable to maintain their reproductive advantage and finally achieved similar overall reproductive performance. Similar results were observed by both Burke and Roche (2007) and Delaby et al. (2009) and suggest that the animals in the MSR and HSR treatments have adapted to the reduced feed allowance by reducing milk production and increasing body condition mobilization without adverse effects on their reproductive function despite reducing feed intake. Burke and Roche (2007) reported that animals selected within seasonal grass-based systems (such as the NZ cows in this study) have the ability to reduce milk energy output when faced with low energy intake and that this may be an acquired genetic feature of these cows.
The increased BW and BCS loss at higher SR has been reported previously (King and Stockdale, 1980; Macdonald et al., 2008a). The lower concentrations of plasma insulin and IGF and increased BHBA for MSR and HSR are consistent with the increased BW and BCS losses of these treatments and reflect the reduced feed allowance and consequently greater negative energy balance suffered by MSR and HSR in early lactation. McCarthy et al. (2007) reported that increased SR had no effect on plasma insulin, IGF, BHBA, or NEFA compared with a lower SR at MSD; however, unlike in this study, the high SR group had higher blood insulin concentrations during the breeding season. The beneficial effect of earlier calving on late lactation BW and BCS gain has been reported previously (Dillon et al., 1995) and can be explained by the comparatively later stage of lactation of the EC treatment at drying off, which resulted in increased nutrient partitioning to BW and BCS (Horan et al., 2005). The higher herbage allowance of the $\mathrm{LC}$ treatment in early lactation resulted in increased nadir BW and reduced BW loss from calving to AI and calving to nadir. The increased IGF and insulin concentration of the EC treatments is expected given the increased level of concentrate supplementation of EC compared with LC treatments (de Feu et al., 2009).

The relationship between nutritional level and animal health and reproductive performance is complex and responses are often variable and inconsistent (Horan et al., 2004; Taylor et al., 2004; de Feu et al., 2009). Stocking rate had no effect on clinical mastitis, SCC, calving difficulty, or lameness. Similarly, SR had no effect on any indicators of immunosuppression, including neutrophil and lymphocyte percentages. Olmos et al. (2009) also observed no effect of feeding level on postpartum health and immunocompetence among grass-fed dairy cattle in early lactation.

\section{Effect of Genetic Strain}

Animals selected for a combination of milk productivity and reproductive traits within grass-based systems of production have superior reproductive capacities compared with animals selected for milk production alone (Horan et al., 2004; Macdonald et al., 2008b; Coleman et al., 2009). In a retrospective analysis comparing pregnant and nonpregnant cows within this study, pregnant cows had a higher genetic potential for fertility (fertility sub-index) and overall EBI compared with nonpregnant animals. This confirms that, in contrast to the lack of influence of SR and CD, genetic selection using the EBI index had an important positive effect on reproductive performance. Although the average EBI of each group in the present study was high (€116), and after account- 
ing for the effect of fertility sub-index, the NZ strain tended to have superior reproductive performance and lost less BCS than the NA strain. Similar to other studies (Hansen, 2000), the increased milk volume capability of the NA HF resulted in lowered BCS at nadir, at $\mathrm{AI}$, and at the end of lactation and greater BCS loss from calving to AI. The reduced BCS loss postcalving of the NZ strain has been reported previously (Horan et al., 2005; Macdonald et al., 2008b), whereas Roche et al. (2006) reported that the NZ strain gained BCS more rapidly post-nadir compared with NA animals. McCarthy et al. (2007) also observed that the superior BCS of NZ cows is reflected in higher IGF and insulin concentrations compared with NA cows, whereas Lucy et al. (2009) concluded that the higher IGF and insulin concentrations of the NZ strain, in particular, was a good indicator of their superior postpartum energy balance and provided further evidence of the greater apparent suitability of this strain within intensive grassbased systems.

Higher submission rates and rates of pregnancy in the first 6 wk of breeding for NZ cows have been reported previously (Horan et al., 2004; Macdonald et al., 2008b), whereas the presence of strain of HF by SR interactions for fertility traits has rarely been observed. A genotype by environment interaction is defined as "the phenomenon that performances of different genotypes are not equally affected by different environments" (Falconer, 1952). The presence of a significant strain by SR interaction for pregnancy rate to first service arises due to the comparably poorer results of the NA strain in the high SR and further substantiates previous findings that the reproductive capacity of the NA strain is reduced within intensive grass-based systems (Horan et al., 2004; Macdonald et al., 2008b). In addition, and in contrast to the NZ strain, the requirement for reproductive intervention among NA cows also tended to increase as SR increased. Taking these findings with those of Cutullic et al. (2011), these results suggest that the NZ strain, selected from a pastoral environment, has adapted more robustly to intensive pastoral grazing systems with low levels of supplementary feed by reducing milk production to maintain BCS and reproductive efficiency within such systems. Although the overall benefits of genetic selection using the EBI are evident from this study, the presence of genotype by environment interactions for reproductive traits further emphasizes the importance of selecting germplasm from within the intended management system.

\section{CONCLUSIONS}

The overall pregnancy rate and health of predominantly grass-fed cows in the current study was unaf- fected by CD or SR, although increased SR may lead to a greater requirement for artificial hormonal intervention. Although having no effect on overall pregnancy rates or general health of the animal, earlier calving and increased SR reduce feed allowance and consequently reduce BW and BCS in early lactation. Strain of HF had a significant effect on the results observed, as animals of NZ ancestry maintained a higher BCS throughout lactation and tended to have superior reproductive performance compared with animals of NA ancestry. The existence of a SR by strain interaction for several reproductive variables suggests that the NZ strain is more suited to intensive grazing systems and can cope better with potentially reduced feed allowances at increased SR. The results also suggest that increased SR can be achieved without any adverse effects on overall pregnancy rate when appropriate animals are selected.

\section{ACKNOWLEDGMENTS}

We acknowledge the financial support of the Irish Dairy Levy and we thank the staff of Curtin's farm and the many summer students for their co-operation, care, and management of the experimental animals. We also thank J. Kenneally, F. Coughlan, and M. Feeney (Animal and Grassland Research and Innovation Centre, Teagasc, Moorepark, Ireland) for their technical assistance over the course of the study.

\section{REFERENCES}

Auldist, M. J., M. F. S. Pyman, C. Grainger, and K. L. Macmillan. 2007. Comparative reproductive performance and early lactation productivity of Jersey $\times$ Holstein cows in predominantly Holstein herds in a pasture-based dairying system. J. Dairy Sci. 90:48564862 .

Baudracco, J., N. Lopez-Villalobos, C. W. Holmes, and K. A. Macdonald. 2010. Effects of stocking rate, supplementation, genotype and their interactions on grazing dairy systems: A review. N. Z. J. Agric. Res. 53:109-133.

Burke, C. R., and J. R. Roche. 2007. Effects of pasture feeding during the periparturient period on postpartum anovulation in grazed dairy cows. J. Dairy Sci. 90:4304-4312.

Burke, C. R., Y. J. Williams, L. Hofmann, J. K. Kay, C. V. C. Phyn, and S. Meier. 2010. Effects of an acute feed restriction at the onset of the seasonal breeding period on reproductive performance and milk production in pasture-grazed dairy cows. J. Dairy Sci. 93:1116-1125.

Coleman, J., K. M. Pierce, D. P. Berry, A. Brennan, and B. Horan. 2009. The influence of genetic selection and feed system on the reproductive performance of spring-calving dairy cows within future pasture-based production systems. J. Dairy Sci. 92:5258-5269.

Coleman, J., K. M. Pierce, D. P. Berry, A. Brennan, and B. Horan. 2010. Increasing milk solids production across lactation through genetic selection and intensive pasture-based feed system. J. Dairy Sci. 93:4302-4317.

Cutullic, E., L. Delaby, Y. Gallard, and C. Disenhaus. 2011. Dairy cows' reproductive response to feeding level differs according to the reproductive stage and the breed. Animal 5:731-740.

de Feu, M. A., A. C. O. Evans, P. Lonergan, and S. T. Butler. 2009. The effect of dry period duration and dietary energy density on 
milk production, bioenergetic status, and postpartum ovarian function in Holstein-Friesian dairy cows. J. Dairy Sci. 92:6011-6022.

Delaby, L., P. Faverdin, G. Michel, C. Disenhaus, and J. L. Peyraud. 2009. Effect of different feeding strategies on lactation performance of Holstein and Normande dairy cows. Animal 3:891-905.

Dillon, P., S. Crosse, G. Stakelum, and F. Flynn. 1995. The effect of calving date and stocking rate on the performance of springcalving dairy cows. Grass Forage Sci. 50:286-299.

Dillon, P., T. Hennessy, L. Shalloo, F. Thorne, and B. Horan. 2008 Future outlook for the Irish dairy industry: A study of international competitiveness, influence of international trade reform and requirement for change. Int. J. Dairy Technol. 61:16-29.

Edmonson, A. J., I. J. Lean, L. D. Weaver, T. Farver, and G. Webster. 1989. A body condition scoring chart for Holstein dairy cows. J. Dairy Sci. 72:68-78.

Falconer, D. S. 1952. The problem of environment and selection. Am. Nat. 86:293-300.

Grimard, B., S. Féret, A. Chevallier, A. Pinto, C. Ponsart, and P. Humblot. 2006. Genetic and environmental factors influencing first service conception rate and late embryonic/foetal mortality in low fertility dairy herds. Anim. Reprod. Sci. 91:31-44.

Hansen, L. B. 2000. Consequences of selection for milk yield from a geneticist's viewpoint. J. Dairy Sci. 83:1145-1150.

Hoden, A., J. L. Peyraud, A. Muller, L. Delaby, and P. Faverdin. 1991. Simplified rotational grazing management of dairy cows: Effects of rates of stocking and concentrate. J. Agric. Sci. 116:417-428.

Horan, B., P. Dillon, D. P. Berry, P. O'Connor, and M. Rath. 2005 The effect of strain of Holstein-Friesian by pasture-based feed system interaction for milk production, body weight and body condition score. J. Dairy Sci. 88:1231-1243.

Horan, B., J. F. Mee, M. Rath, P. O'Connor, and P. Dillon. 2004. The effect of strain of Holstein-Friesian cow and feed system on reproductive performance in seasonal-calving milk production systems. Anim. Sci. 79:453-467.

Kennedy, E., M. McEvoy, J. P. Murphy, and M. O'Donovan. 2009. Effect of restricted access time to pasture on dairy cow milk production grazing behavior, and dry matter intake. J. Dairy Sci. 92:168-176.

Kennedy, J., P. Dillon, K. O'Sullivan, F. Buckley, and M. Rath. 2003. The effect of genetic merit for milk production and concentrate feeding level on the reproductive performance of Holstein-Friesian cows in a grass-based system. Anim. Sci. 76:297-308.

King, K. R., and C. R. Stockdale. 1980. The effects of stocking rate and nitrogen fertiliser on the productivity of irrigated perennial pasture grazed by dairy cows. 2 . Animal production. Aust. J. Exp. Agric. Anim. Husb. 20:537-542.

Lips, M., and P. Rieder. 2005. Abolition of raw milk quota in the European Union: A CGE analysis at the member country level. J. Agric. Econ. 56:1-17.

Lucy, M. C., G. A. Verkerk, B. E. Whyte, K. A. Macdonald, L. Burton, R. T. Cursons, J. R. Roche, and C. W. Holmes. 2009. Somatotropic axis components and nutrient partitioning in genetically diverse dairy cows managed under different feed allowances in a pasture system. J. Dairy Sci. 92:526-539.

Macdonald, K. A., J. W. Penno, J. A. S. Lancaster, and J. R. Roche. 2008a. Effect of stocking rate on pasture production, milk production, and reproduction of dairy cows in pasture-based systems. J. Dairy Sci. 91:2151-2163.

Macdonald, K. A., G. A. Verkerk, B. S. Thorrold, J. E. Pryce, J. W Penno, L. R. McNaughton, L. J. Burton, J. A. S. Lancaster, J. H. Williamson, and C. W. Holmes. 2008b. A comparison of three strains of Holstein-Friesian grazed on pasture and managed under different feed allowances. J. Dairy Sci. 91:1693-1707.

McCarthy, B., L. Delaby, K. M. Pierce, F. Journot, and B. Horan. 2011. Meta-analysis of the impact of stocking rate on the productivity of pasture-based milk production systems. Animal 5:784794.

McCarthy, S., D. P. Berry, P. Dillon, M. Rath, and B. Horan. 2007. Effect of strain of Holstein-Friesian and feed system on calving performance, blood parameters and overall survival. Livest. Sci. 111:218-229.

McDougall, S., C. R. Burke, N. B. Williamson, and K. L. MacMillan. 1995. The effect of stocking rate and breed on the period of postpartum anoestrum in grazing dairy cattle. Proc. N.Z. Soc. Anim. Prod. 55:236-238.

O'Donnell, S., L. Shalloo, A. M. Butler, and B. Horan. 2008. A survey analysis of opportunities and limitations of Irish dairy farmers. J. Farm Manage. 13:1-15.

Olmos, G., J. F. Mee, A. Hanlon, J. Patton, J. J. Murphy, and L. Boyle. 2009. Peripartum health and welfare of Holstein-Friesian cows in a confinement-TMR system compared to a pasture-based system. Anim. Welf. 18:467-476.

Pedernera, M., S. C. Garcia, A. Horagadoga, I. Barchia, and W. J Fulkerson. 2008. Energy balance and reproduction on dairy cows fed to achieve low or high milk production on a pasture-based system. J. Dairy Sci. 91:3896-3907.

Roche, J. R., D. P. Berry, and E. S. Kolver. 2006. Holstein-Friesian strain and feed effects on milk production, body weight, and body condition score profiles in grazing dairy cows. J. Dairy Sci. 89:3532-3543.

SAS Institute. 2006. User's Guide: Statistics. Version 9.1. SAS Institute Inc., Cary, NC.

Taylor, V. J., Z. Cheng, P. G. A. Pushpakumara, D. E. Beever, and D. Wathes. 2004. Relationships between the plasma concentrations of insulin-like growth factor-1 in dairy cows and their fertility and milk yield. Vet. Rec. 155:583-588.

Van Berkum, S., and J. Helming. 2006. European Dairy Policy in the Years to Come: Impact of Quota Abolition on the Dairy Sector. Agricultural Economic Research Institute, The Hague, the Netherlands.

Wales, W. J., P. T. Doyle, and D. W. Dellow. 1998. Dry matter intake and nutrient selection by lactating cows grazing irrigated pastures at different pasture allowances in summer and autumn. Aust. J. Exp. Agric. 38:451-460. 